\title{
DECOMPENSATED AORTIC STENOSIS IN A YOUNG PATIENT WITH MULTIPLE COMORBIDITIES - A CASE REPORT
}

\author{
ALEXANDRA STOICA ${ }^{1}$, MARIUS HARPA ${ }^{2}$, HUSSAM AL HUSSEIN ${ }^{3}$, CARMEN OPRIŞ $^{4}$, \\ COSMIN OPRIŞ ${ }^{5}$, HAMIDA AL HUSSEIN ${ }^{6}$, CLAUDIU GHIRAGOSIAN ${ }^{7}$, COSMIN BANCEU $^{8}$, \\ HORAŢIU SUCIU ${ }^{9}$
}

2,3,6,7,8,9 University of Medicine, Pharmacy, Science and Technology of Târgu-Mureș, ${ }^{1,2,3,4,5,7,8,9}$ Emergency Institute for Cardiovascular Diseases and Transplantation of Târgu-Mureș

Keywords: aortic stenosis, heart failure, aortic valve replacement, pulmonary thromboembolism

\begin{abstract}
Aortic valve replacement is a safe therapy that can reverse cardiac remodeling and increase cardiac contractility, improve symptoms and quality of life. We presented a case of a 35-year-old male patient admitted to the Emergency Institute for Cardiovascular Disease and Transplantation of Târgu Mureș, Romania, due to severe aortic stenosis with severely depressed ejection fraction, left atrial myxome and a history of deep vein thrombosis and pulmonary thromboembolism. He underwent excision of the aortic valve and replacement with a mechanical prosthesis, excision of left atrial myxoma and tricuspid annuloplasty. The postoperative evolution was favourable with a significant recovery of the left ventricular systolic function and regression of cardiac symptomatology. This case was particular due to the rapid progression of the aortic pathology with the reduction of cardiac (systolic) function in a relatively short time as well as the occurrence of the thromboembolic event unrelated to the left atrial myxoma and rather associated with the background of cardiac failure with low cardiac output
\end{abstract}

\section{INTRODUCTION}

Aortic stenosis (AS) is the most common valvular heart disease in developed countries. It predominantly affects males and its prevalence increases with age.(1) The most common etiologies of AS are calcification due to degenerative process, bicuspid aortic valve (BAV) and rheumatic disease. Symptoms develop gradually and include dyspnea, syncope and angina pectoralis.(2) With the onset of symptoms, the survival rate decreases considerably in the absence of surgical treatment.(1-2)

\section{CASE REPORT}

A 35-year-old male patient was admitted to the Emergency Institute for Cardiovascular Disease and Transplantation (IuBCvT) of Târgu-Mureș, România, Department of Cardiovasculary Surgery for cardiac decompensation and significant weight loss over the last 4 weeks. One month prior to presentation, the patient had symptoms suggestive of angina, dyspnea and fatigue on medium exertion. Transthoracic echocardiography (TTE) at that time revealed severe AS with BAV, moderate aortic regurgitation (AR), slightly diminished global contractility with an ejection fraction (EF) of $45 \%$ and a left atrial mass attached to the atrial septum, measuring $2 \times 4 \mathrm{~cm}$ and an area of $6.6 \mathrm{~cm} 2$. The patient also had a history of deep venous thrombosis (DVT) with pulmonary thromboembolism (PTE) in multiple locations in the right middle and lower lobes, confirmed on CT angiography (figure no. 1). On admission, the patient showed signs and symptoms of NYHA functional class IV heart failure. On physical examination all findings were normal, except for a grade IV/6 systolic murmur at the primary aortic area. Electrocardiography showed sinus rhythm with $90 \mathrm{bpm}$. Laboratory tests revealed moderate hepatorenal dysfunction. TTE revealed dilated cardiomyopathy (DCM) with severely decreased ventricular contractility, an EF of $30 \%$, severe AS with moderate AR, moderate/severe functional tricuspid regurgitation (TR), severe secondary pulmonary hypertension, the mass in the left atrium having the same size, with no signs of growth or mobility. The coronary arteries presented no lesions on coronary angiography. Following all examinations and after hemodynamic stabilization, it was decided that the best course of treatment was a surgical intervention.

Median sternotomy was performed and cardiopulmonary bypass was established with arterial cannulation of the ascending aorta and bi-caval venous cannulation under normothermic conditions. An aortotomy was performed and anterograde ostial cardioplegia was administered, arresting the heart in diastole.

On inspection, the aortic valve showed severely calcified and degenerated leaflets, while the tricuspid valve was mobile with a dilated annulus. A transseptal tumour approach was performed and the smooth, ovoid-fusiform mass was resected. The aortic valve was then excised and replaced with a Saint Jude Medical no. 23 mechanical prosthesis. Tricuspid annuloplasty was performed using a Medtronic 3D ring.

The septum and the right atriotomy were closed using a 3.0 Prolene double-layered running suture, while the aortorrhaphy was performed using 4.0 Prolene double-layered running suture. After aortic de-clamping and reperfusion, spontaneous sinus rhythm was obtained.

${ }^{2}$ Corresponding author: Marius Harpa, Str. Ghe. Marinescu, Nr. 38, Târgu-Mureş, România, E-mail: marius_harpa@umfst.ro, Phone: +40740 311396 Article received on 18.04.2020 and accepted for publication on 02.06.2020 
Figure no. 1. CT angiography showing pulmonary infarction in the right middle lobe due to PTE

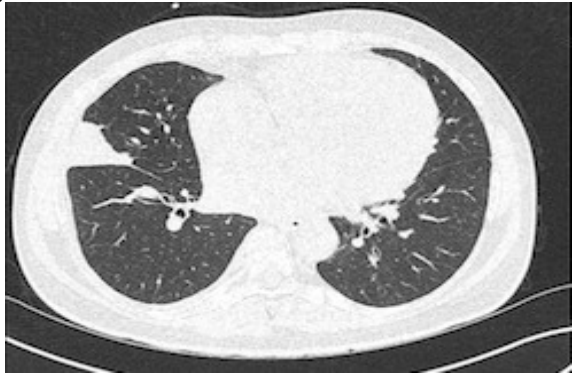

RESULTS

Postoperatively, the patient presented a slow favourable evolution that required monitoring and supportive treatment of the associated comorbidities, with progressive improvement of the cardiovascular status. The amelioration of cardiac output and the reduction of the hepatic stasis led to remission of the hepatorenal dysfunction.

Postoperative TTE examination revealed a right ventricular floating thrombus, probably due to the presence of the Swan Ganz catheter, with ulterior resolution after anticoagulation therapy (figure no. 2), a normally functioning prosthetic aortic valve, mild TR (figure 3), no signs of residual tumour and an $\mathrm{EF}$ of $30 \%$.

At 6-month follow-up, a significant improvement in quality of life was observed, with regression of cardiac symptomatology and a normal clinical and biological status without organ dysfunction or other thromboembolic events. TTE showed a significant recovery of the left ventricular (LV) systolic function with an EF of $45 \%$, and all other parameters within normal limits.

Figure no. 2. Transthoracic echocardiography. Apical fourchamber view showing a mobile mass attached to the tricuspid valve chordae

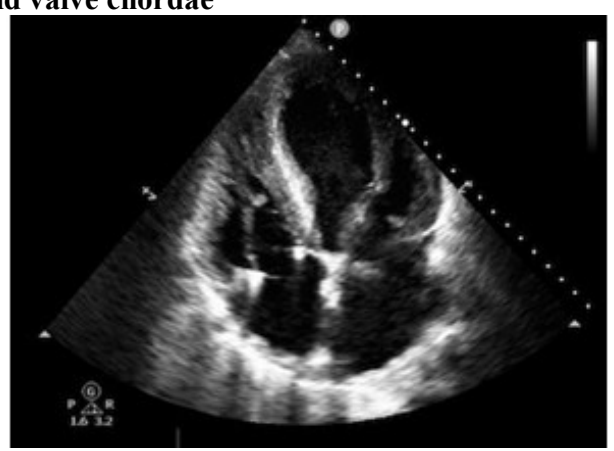

Figure no. 3. Transthoracic echocardiography. Apical fourchamber view with colour Doppler showing mild TR after tricuspid annuloplasty

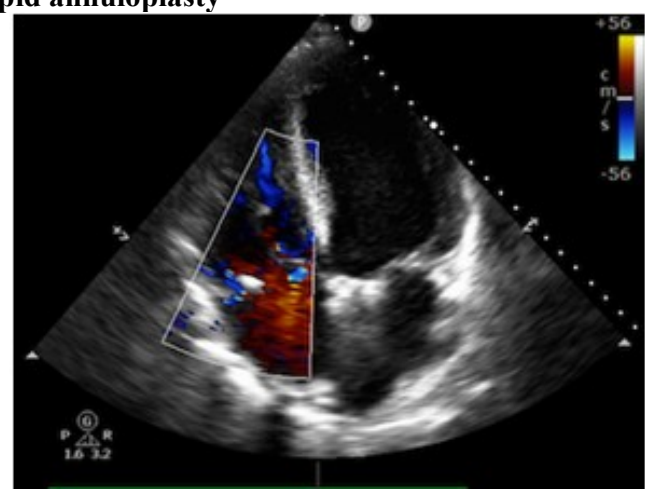

DISCUSSIONS

According to literature data, the onset of heart failure as a consequence of AS is associated with a high mortality rate in the absence of surgical treatment, especially among patients who have AS with a reduced EF.(3)

Initially, the LV responds to the pressure overload with concentric hypertrophy, maintaining a normal or even increased EF.(4) With progression of the AS, in advanced stages, the LV chamber dilates which results in developing DCM and congestive heart failure (CHF).(5)

The role of CHF is recognized in the development of DVT through the decreased cardiac output, with the risk of developing subsequent complications like PTE.(6-7)

In the presented case, the severe AS rapidly progressed to CHF and the patient developed DVT and PTE.

According to a study that assessed the long-term survival and ventricular systolic function after aortic valve replacement, a significant $\mathrm{EF}$ improvement and important amelioration of clinical status and symptomatology were observed.

Although patients with severe AS and CHF present a less favourable outcome, in the absence of contraindications, surgical aortic valve replacement should be considered.(8)

In the presented case, a postoperative improvement in $\mathrm{EF}$ and NYHA functional class was observed in a patient with severe AS, DCM and CHF.

Patients who develop severe AS have a long asymptomatic period, in which mortality is reduced. With the onset of symptoms, survival rate decreases considerably in the absence of surgical treatment.(9)

In patients with AS who develop heart failure, the progression of the disease from the onset of symptoms to time of death is approximately 2 years.(10)

According to a study regarding the natural history of the disease, in asymptomatic patients with severe AS, surgery may be delayed until the onset of symptoms. A rapidly progressive evolution can be observed in patients with severe AS associated with calcification of the aortic valve, these patients having a poorer prognosis.(11)

Surgery is a safe therapy that can reverse cardiac remodeling and increase cardiac contractility, improve symptoms and quality of life.(12) Before performing the surgical treatment, heart failure should be treated, stabilizing the hemodynamic, clinical and biological status.(13)

\section{CONCLUSIONS}

The particularity of this case is represented by the rapid progression of the aortic pathology with the reduction of cardiac systolic function in a relatively short time, the occurrence of the thromboembolic event unrelated to the left atrial myxoma and rather associated with the background of cardiac failure with low cardiac output, as well as the onset of the hepatorenal dysfunction.

\section{REFERENCES}

1. Alec V, Ottavio A, Felicita A, et al. The joint Task force on the Manangement of Valvular Heart Disease of The European Society of Cardiology and the European Association for Cardio-Thoracic Surgery. European Heart Journal. 2012;33(19): 2463

2. Cohn L. Cardiac Surgery in the Adult 4 Edition. McGrawHill Education/Medical; 2011. p. 668-669.

3. Zile MR, Gaasch WH. Heart Failure in Aortic StenosisImproving diagnosis and treatment. $\mathrm{N}$ Engl $\mathrm{J}$ Med. 2003;348:1735-1736.

4. Ginghina C. Mic tratat de cardiologie. Ed Academiei Române; 2010. p. 405-406. 


\section{CLINICAL ASPECTS}

5. Gherasim L, Apetrei E, Bălănescu S, et al. Bolile aparatului cardiovascular. Editura Medicală București; 1996. p. 322

6. Gregory P, Samuel Z. Pulmonary Embolism in Heart Failure. Circulation. 2008;118:1598-1601.

7. Darze ES, Latado AL, Guimaraes AG, et al. Acute pulmonary embolism is an independent predictor of adverse events in severe decompensated heart failure patients. Chest. 2007;31:1838-1843.

8. Neale S, John H, Shahbudin H, et al. Severe aortic stenosis with impaired left ventricular function and clinical heart failure: Results of Valve Replacement. Circulation. 1978;58(2):255-263.

9. Ross J Jr, Braunwald E. Aortic stenosis. Circulation. 1968;137:2099-2100.

10.Spitzer E, Hahn R, Pirabot P, de Vries T, et al. Aortic Stenosis and Heart Failure: Disease Ascertainment and Statistical Considerations for Clinical Trials, Card Fail Rev. 2019;5(2):99-105.

11.Rosenhek R, Binder T, Porenta G. Predictors of outcome in severe asymptomatic aortic stenosis. N Engl J Med. 2000 Aug 31;343(9):611-7.

12.Christakis GT, Joyner CD, Morgan CD et al. left ventricular mass regression after aortic valve replacement. Ann Thorac Surg. 1996;62(4):1084-9.

13.Brian R. Lidman, Robert O. Bonow, Catherine M. Otto, Current Management of Calcific Aortic Stenosis. Circ Res. 2013;113(2):223-237 